\title{
Assessing the Effect of Oil Price Shock Using an Energy-Economy Decision Model with Technology Characteristics
}

\author{
Chin-Wen Yang $^{1}$ Chung-Huang Huang ${ }^{2}$ Shih-Mo Lin \\ ${ }^{1}$ Institute of Industrial Economics, National Central University \\ ${ }^{2}$ Department of Economics, National Tsing-Hua University \\ ${ }^{3}$ Department of International Trade, Chung Yuan Christian University
}

\begin{abstract}
The significant jump in world crude oil price over the past year has raised great concern over the economic impact that such a price shock may bring about on Taiwan's economy, which has been characterized by extremely high import-oil dependence. Previous analyses have been tackling similar issue from several different angles, but it has rarely been discussed from a complete view of interactions among industries, energy, and technology choices. This paper tries to fill this void by using an energy-economy decision model, TaiSEND, which is constructed specifically for energy shock and policy analysis. As an integrated top-down/bottom-up CGE model, TaiSEND has demonstrated to have advantage over other type of models in figuring out how the technology adoption decision may change under given world crude oil price shocks.
\end{abstract}

Keywords: Oil price shock, CGE model, technology choice.

\section{Introduction}

The world crude oil price had been increasing from $\$ 25$ per barrel in 2001 to $\$ 50$ per barrel in 2005. The economic impact of such a price shock on Taiwan, whose economy is characterized by $50.76 \%$ oil and $99.91 \%$ import-oil dependence, is deeply concerned.

Some of the previous researches about the impacts of crude oil price shocks, such as Cunado and Gracia (2005) and Brown and Yücel (2002), have been focusing on the interactions between energy, economic behavior and macroeconomic policy. On the other hand, Chang and Wong (2003), Cuñado and Gracia (2003), and Ferderer (1996) have paid much attention on the macroeconomic effects of oil price uncertainties. The results of the above-mentioned researches indicate that oil price fluctuations usually induce sustained and obvious inflations, and have only limited and unsymmetrical impacts on production behavior, which means that an increase in oil price will cause negative economic effects while a decrease one will have no positive gains.

In some other studies, Huang, Hwang, and Peng (2005) used the data of U.S.A, Canada and Japan to analyze the threshold effect of oil price impact, and found that there existed threshold effects. This implies that oil price changes will have limited impacts when oil price below the threshold and the optimum level of threshold can be changed through import policy and technology adoption strategy.

Although analyzing the same issue from different angles, the methodologies used by these researches are mostly econometric methods and have no way in describing the detailed transmitting process from initial international crude oil price change to final domestic economic impacts. This paper tries to fill this void by using an integrated model TaiSEND (Taiwan Sustainable Energy Decision model ).

As a top-down/bottom-up integrated assessment model, TaiSEND links a country level CGE model and a detailed technology decision model to describe the interactions between generation technologies, the power sector, energies, and all the other sectors of the economy. The theoretical foundation of TaiSEND as well as the structure of database of it will be briefly discussed in the next section, followed by oil price shock scenarios and simulation results.

\section{The TaiSEND Model}

In evaluating issues related to "sustainability", a model that can capture the complex interactions between energy and the economy is required. 
This model needs to be specified with a consistent methodological framework that takes into account the essential system constraints in an economy-wide way, and at the same time, retains a certain level of detail with regard to energy sector.

For more than two decades, computable general equilibrium (CGE) models constructed with detailed specifications on energy sectors have become popular tools in analyzing energy policy issues. Most of these models, due to their standardized specification of production technology, however, are incapable of dealing with the possibility of emerging and phasing out of energy technologies that could have represented a natural choice by firms in their long-term decision-making.

Recently, this incapability has been overcome to a great degree by the incorporation of bottom-up activity analysis into the top-down CGE models by using a complementarity format (e.g., Frei, 2001; Böhringer, 1998). The complementarity format is used to describe the hybrid nature of production technologies existed in an economy in which energy sectors are represented by (bottom-up) activity analysis and the other sectors are represented by usual (top-down) smooth production functions.

Merging bottom-up and top-down models moves the analysis of energy and environmental issues a step forward by allowing for the possibility of introducing alternative technologies and a temporary or permanent termination of an existing technology by sectors.

In our preliminary model, only electricity generation sector holds the form of activity analysis. For this specific sector, equilibrium between demand and (bottom-up) supply determines the dispatching of available technologies and the market price. Figure 1 illustrates this situation, in which the bottom-up supply curve is characterized by technology-specific short-run marginal costs.

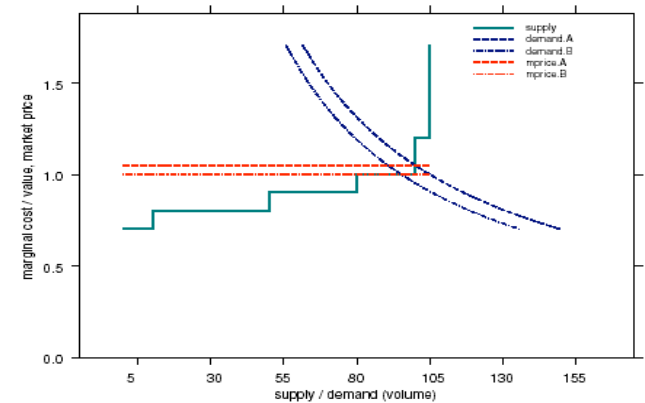

Figure 1. Equilibrium for the bottom-up technologies

Source: Frei (2001).
Another model specification and policy analysis issue that needs to be taken into account in energy and environmental policy assessment is the dynamic behavior of economic agents within the economy. Dynamic formulation that incorporates endogenously the investment decision by sectors traces the evolution of capital stocks and technology mixes.

The endogenous treatment of the evolution of technology-specific capital stock takes into account the physical depreciation of existing capital stock, the sectoral allocation of investment, and the allocation of investment within the sector (i.e., the allocation of investment between different technologies).

\section{Benchmark Database}

The major benchmark data sets of the current version of the TaiSEND model are a 1999 social accounting matrix (SAM) for Taiwan and a set of technology data for electricity generation technologies. There are 21 sectors (listed in table 1) in our SAM, and they can be split to energy sectors and non-energy sectors. In addition to power sector, energy sectors include three types of primary energy (coal, crude oil, and natural gas) and six types of derived energy (coal product, gasoline, diesel oil, jet fuel, fuel oil, and other petroleum products).

In order to fit the bottom-up power generator design in our model, power sectors are divided into generation and transmission parts. Generation part includes 9 sorts of technologies which are discriminated according to unit energy usage characteristics. These technologies are hydro-power, thermal-power-oil, thermal-power-coal, thermal-power-gas, nuclear, cogeneration, biomass, solar-thermal, and wind-power.

All of these technologies generate the same product - electricity, and all of their outputs go to transmission part and distributed (sold) to other non-power sectors by transmission sector. In base year, biomass, solar-thermal, and wind-power do not operate yet, because their generation costs are higher than electricity dispatched price. Our margin technology whose available capacity is not fully operated is thermal-power-gas.

Most data of our SAM are from input-output table from Directorate-General of Budget, Accounting and Statistics (DGBAS), Executive Yuan, energy usage data from Bureau of Energy, and power generation technology data from Taiwan power company. 


\section{Design of Scenarios}

The benchmark year of the model is 1999 and the simulation period is from 2000 to 2012. Two scenario groups are specified as follows.

\section{Scenario 1 - Baseline}

Based on GDP forecasts from other researches and the international energy prices forecasts from USDOE/EIA, we set up a baseline scenario, with which other simulation scenarios can compare.

\section{Scenario 2 - Crude oil price shocks}

This scenario simulates that international crude oil price will increase by $25 \%, 50 \%, 75 \%$, and $100 \%$ from 2005 onward.

\section{Results and Analysis}

When crude oil price increases by $25 \%, 50 \%$, $75 \%$, and $100 \%$ relative to base case in 2005 , GDP growth rate will be $0.38 \%, 0.70 \%, 0.96 \%$, and $1.19 \%$ in magnitude less than the baseline (figure 2).

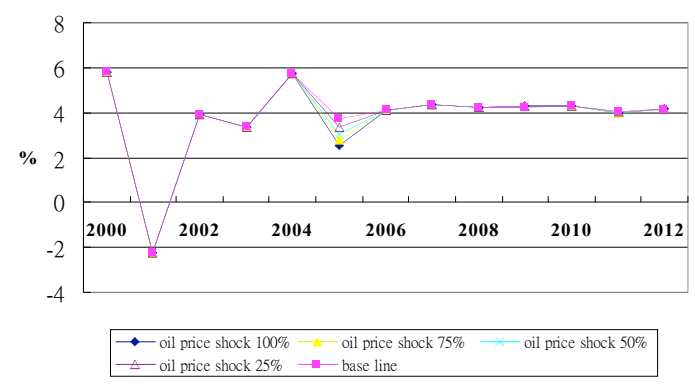

Figure 2. GDP growth rate

In our model, the cheapest technology (with lowest unit generation cost) will operate first until its available capacity is fully used. Thus the market demand will determine dispatched price and those technologies whose unit cost are lower than this dispatched price will fully employ their capacities. The one with highest generation cost in operating technologies is called margin technology.

In baseline, with GDP growing, industrial development induces the demand for energy and electricity. To satisfy this demand increase, the output of margin technology needs to increase. From Figure 3, except for the negative GDP growth in 2001 and the significant oil price fluctuations in 2004, the generation of thermal-power-gas have kept raising till its capacity is fully used in 2012 .

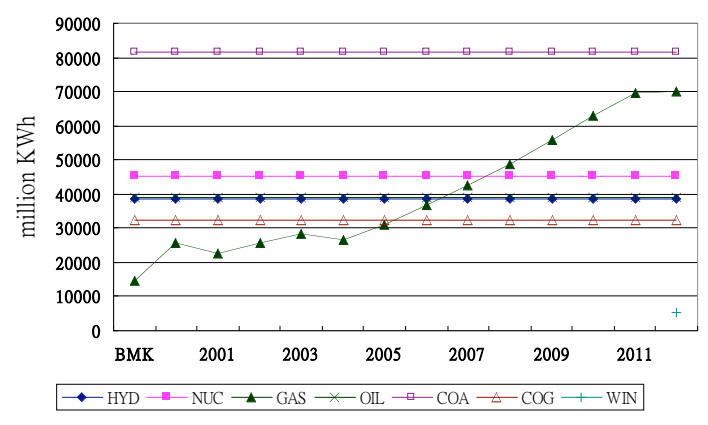

Figure 3. Generation outputs by technologies

Meanwhile, to support the $5.8 \%$ GDP growth in 2000, short-term capacity of thermal-power-gas needs to expand and reaches long-term capacity limit in 200 . When oil price keeps rising from 2004 to 2005, generation cost and dispatched price of electricity will be getting higher, and some renewable energies will become profitable. In our simulation results, the first renewable energy generator will be installed in 2004 (biomass), and wind-power and solar-thermal follow in 2009.

Margin technology generation outputs under different oil price shocks show similar trend, but the larger the shock, the less addition of output that the thermal-power-gas will generate, making the time wind-power joins to operate longer.

The time needs for the renewable energy generators to be installed will be longer too when oil price shocks get larger. For example, the biomass shows to be installed in 2004 and expanded in 2006 in the baseline, but the expansion will be delayed to 2008 as show in figure 4 , which reveals the results of an oil price shock of $100 \%$ relative to the baseline.

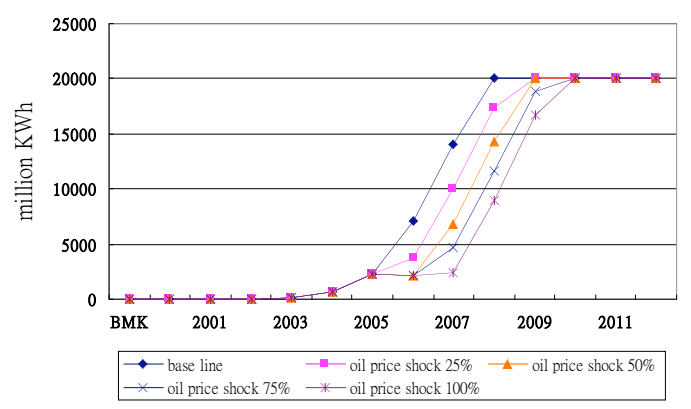

Figure 4. Biomass installed capacities (with $25 \%$ to $100 \%$ oil price shocks)

\section{Conclusions}

Taiwan has made considerable efforts over the past decade to build both top-down (e.g. TAIGEM-III) and bottom-up (e.g. 
MARKAL-TAIWAN) policy evaluation models to accommodate the increasing needs in energy and environmental policy analysis.

By knowing the limitations of both kinds of models in practical policy analysis and that they could actually complement to each other, there is no doubt that an integrated model must be built eventually.

TaiSEND model represents such an endeavor and is applied to some policy simulations such as assessing the effect of international oil price shocks.

From the simulation results shown in previous section, we found that significant changes in technology adoption decision shall occur under given world crude oil price shocks. When import energies become more and more expensive, renewable energy generators will become profitable and be installed eventually. However, when oil price increases, energy demand will also cut down, which might cause the time of adoption and expansion of renewable energy generators to become longer.

\section{References}

[1] Böhringer, C., The synthesis of bottom-up and top-down in energy policy modelling, Energy Economics 20(3), 233-248, 1998.

[2] Brown, S. P. A. and M. K. Yücel, "Energy Prices and Aggregate Economic Activity: An Interpretative Survey", The Quarterly Review of Economics and Finance 42, 193-208, 2002.

[3] Chang, Y. and J. F. Wong, "Oil Price Fluctuations and Singapore Economy", Energy Policy 31, 1151-1165, 2003.

[4] Cuñado, J. and F. P. de Gracia, "Do Oil Price Shocks Matter? Evidence for Some European Countries", Energy Economics 25, 137-154, 2003.

[5] Cunado, J. and F. Perez de Gracia, "Oil Prices, Economic Activity and Inflation: Evidence for Some Asian Countries", The Quarterly Review of Economics and Finance, 45, 65-83, 2005.

[6] Ferderer, J. P., "Oil Price Volatility and The Macroeconomy", Journal of Macroeconomics, Winter 1996, Vol. 18, No. 1, pp. 1-26, 1996.

[7] Frei, C.F., Bottom-up activity analysis in a computable general equilibrium framework: case of electricity, Thesis No. 2327, Swiss Federal Institute of Technology Lausanne (EPFL), Lausanne, 2001.

[8] Huang, B. N., M. J. Hwang, and H. P. Peng, "The Asymmetry of The Impact of
Oil Price Shocks on Economic Activities: An Application of The Multivariate Threshold Model.”, Energy Economics 27, 455-476, 20 
